\title{
Arenas, naming rights e apelidos: estratégias discursivas e modelos de cidade na comunicação do Allianz Parque e da Arena Corinthians
}

\section{Paolo Demuru}

Pós-doutor; Universidade Federal do Pernambuco, Recife, PE, Brasil paolodemuru@gmail.com

\section{Resumo}

Com base em um diálogo entre a Semiótica discursiva greimasiana e pós-greimasiana e a Semiótica da cultura lotmaniana, como também em abordagens que defendem a complementariedade entre as duas e em confrontos mais pontuais com os estudos sobre a glocalização, o presente artigo propõe uma reflexão sobre os nomes e os processos de nomeação dos dois mais novos estádios de São Paulo: a Arena Corinthians e o Allianz Parque. Três são as questões que nos interessa discutir: as consequências semiótico-comunicacionais implícitas na passagem da denominação de estádio para aquela de arena; a reiteração, na cidade, da tendência mercadológica internacional que prevê a venda dos assim chamados naming rights dos estádios para empresas privadas; e a resistência implícita contra tal tendência manifestada por meio da celebração midiática do apelido Itaquerão - razão pela qual, segundo sua diretoria, o clube não teria ainda conseguido vender os direitos de nomeação da Arena.

\section{Palavras-chave}

Estádios. Arenas. Naming rights. Greimas. Lotman. 


\section{Introdução: o objeto, os problemas e a metodologia}

O objetivo do presente artigo é refletir sobre os nomes e os processos de nomeação dos dois mais novos estádios de São Paulo: a Arena Corinthians, do Sport Clube Corinthians Paulista, e o Allianz Parque, da Sociedade Esportiva Palmeiras. Três são as questões que nos interessa discutir: em primeiro lugar, as consequências semiótico-comunicacionais implícitas na passagem da antiga definição de estádio para a mais recente denominação de arena; em segundo lugar, a reiteração e a reafirmação, na cidade, da tendência mercadológica internacional que prevê a venda dos assim chamados naming rights (direitos de nomeação) de estádios novos ou reformados para empresas privadas (como no caso do Allianz Parque); e, em terceiro lugar, a resistência implícita contra tal tendência manifestada através da celebração midiática do apelido Itaquerão - razão pela qual, segundo o ex-presidente do Corinthians, André Sanchez, o clube não teria ainda conseguido vender os direitos de nomeação de sua Arena (VICTORINO, 2013).

Como veremos, estes assuntos remetem a uma problemática Semiótica de ordem glocal, marcada, para parafrasear o teórico da globalização Arjun Appadurai (1996, p. 33), pelo embate entre o "panorama" linguístico-midiático-mercadológico global e o "panorama" linguístico-cultural local. Portanto, nos pareceu oportuno abordá-los com base em um diálogo entre a Semiótica discursiva greimasiana e pós-greimasiana, (GREIMAS; COURTÉS, 1979; LANDOWSKI, 2005; FLOCH, 1995; OLIVEIRA, 2004; 2014a; 2014b) e a Semiótica da cultura lotmaniana (LOTMAN; 1985; 1993), como também em confrontos mais pontuais com os estudos sobre a glocalização (TRIVINHO, 2011; APPADURAI, 1996; ROBERTSON; GIULIANOTTI, 2009; ROSENAU, 2003). Como foi defendido em outras ocasiões (SEDDA, 2012; DEMURU, 2014), a partir de uma perspectiva dialógica que abraça e complementa as propostas de Greimas e Lotman, é possível, pois, desvendar os vínculos profundos entre micro e macro configurações de sentido, particular e universal, local e global. De fato, se a Semiótica da cultura nos ensina a ampliar o olhar e a reconstruir as relações entre os diferentes pedaços de uma ou de mais semiosferas ou entre as tendências homogeneizantes e heterogeneizantes que as atravessam (LOTMAN, 1985; 1990), a Semiótica greimasiana e pós-greimasiana nos fornece um universo interdefinido de conceitos para elaborarmos poderíamos dizer tomando emprestados os célebres termos do antropólogo Clifford Geertz 
(1973, p. 6) - aquelas "descrições densas" que deveriam constituir o ponto de partida das primeiras, a base de generalizações mais profundas e o norte da intepretação das culturas entendidas, como o próprio Geertz auspicava, enquanto universos semióticos. Em outras palavras, trata-se, como aponta Franciscu Sedda, de praticar, via Lotman e Greimas, "um olhar estrábico" (SEDDA, 2006, p. 41), de mergulhar em " [...] um jogo constante e circular de definições internas e externas, de construção de series [...] que estabelecem similaridades e diferenças, de olhares analíticos cada vez mais detalhados e imaginações culturais cada vez mais vastas" (SEDDA, 2012, p. 12, tradução nossa).

É exatamente esta a diretriz que seguiremos no curso do artigo, atrelando análises de objetos de pequeno ou médio porte - uma palavra, um nome, um apelido, a configuração plástica e figurativa da arquibancada dos estádios, a rua e o entorno urbano onde se encontram inseridos - a análises e a reflexões de maior alcance sócio-político-cultural, como aquelas relativas aos cenários midiáticos e econômicos globais. Inicialmente, pela consolidação da primazia, no panorama nacional e internacional, do termo arena em detrimento da antiga definição de estádio.

\section{Estádio versus Arena ou da sublimação linguístico-midiática da paixão torcedora}

Por que os estádios de futebol estão hoje deixando de se chamar estádios? A que se deve a repentina ascensão do termo arena? 0 que implica, em particular, a preferência para esta última? E o que isso tem a ver com as reformas arquitetônicas dos velhos estádios? Está ligada à presença cada vez mais maciça de empresas privadas no mundo do futebol? Ou às suas estratégias de marketing e seus projetos de economia criativa?

A fim de buscar respostas para essas perguntas, partimos de um texto de Peter Sloterdijk, publicado em junho de 2008 na revista Neue Bücher Zeitung (SLOTERDIJK, 2008), no qual o filósofo alemão aborda as diferenças históricas, arquitetônicas e ritualísticas entre estádios e arenas.

A origem dos estádios, afirma Sloterdijk (2008) está relacionada à cultura grega. 0 exemplo mais emblemático é, talvez, o Estádio Panatenaico de Atenas. Sua forma em U, com um lado aberto pela frente, onde situava-se o templo, celebrava a abertura do campo de batalha para os deuses. Os atletas deviam lutar e cumprir seus exercícios diante da presença sancionadora das autoridades divinas, buscando não apenas a vitória, mas também a sime- 
tria dos movimentos e a beleza do gesto atlético, conforme os ideais da época. Quem ganhasse teria direito a uma estatua na Avenida de Olímpia, entrando, assim, no reino da imortalidade.

Diferente do estádio grego, a arena privilegia o espaço fechado e circular. Surgida na Roma Imperial, essa concepção - cuja manifestação mais celebre é o Coliseu - enaltece o patos da imanência, a filosofia da sentença fatal e sem saídas. Dito de outra forma, nenhuma intervenção externa é contemplada na arena. 0 jogo desenvolve-se unicamente perante $o$ povo das arquibancadas, sem intromissões ou julgamentos divinos. É o campo da efemeridade e da brutalidade humana, onde diante do grande público se decretam "[...] derrotas fatais e vitórias no nimbo da crueldade" (SLOTERDIJK, 2008, doc. não paginado, tradução nossa).

Segundo Sloterdijk (2008), assistiu-se, no Século XX, à ascensão e à vitória dos princípios da arena sobre os princípios do estádio. Principalmente no futebol, prevaleceu o culto da força e da selvajaria, razão pela qual, continua o filosofo, "[...] a cultura moderna embarca hoje em um caminho perigoso." (SLOTERDIJK, 2008, doc. não paginado, tradução nossa).

Não nos interessa aqui discutir em detalhes as releituras históricas sloterdijkianas nem nos posicionar a respeito de seus julgamentos ético-morais em relação aos rumos da cultura moderna e contemporânea. No entanto, a reflexão do filosofo alemão pode nos ajudar a compreender melhor as razões e os efeitos do abandono do termo estádio em favor do termo arena.

Ora, é preciso destacar que tal virada semântica ocorre em uma época histórica em que os estádios sofrem transformações profundas tanto no que diz respeito à sua estrutura espacial e arquitetônica - isto é, a sua configuração plástica e figurativa (GREIMAS, 1984; FLOCH, 1995; OLIVEIRA, 2004) - quanto no que tange às suas funções de base. Alterações às quais, acreditamos, a denominação de arena, assim como a entende Sloterdijk, está intimamente vinculada.

Nas formas e nos formatos dos novos estádios, por exemplo, a configuração aberta e circular das arquibancadas atrás do gol foi abandonada para dar lugar a espaços mais fechados e quadrados, como no caso da Arena Corinthians, e, ainda, os degraus de concreto foram substituídos por fileiras de assentos com encosto. Requisito inderrogável para os atuais estádios padrão Fifa, a medida foi implementada pela primeira vez na Inglaterra dos anos de 1990 com o propósito de evitar episódios de violência entre torcidas e acidentes de outro tipo, como aquele que passou a ser conhecido como $O$ Desastre de Hillsborough, em 15 de 
abril de 1989, no estádio homônimo da cidade de Sheffield1․ Uma metamorfose plástica que, se por um lado parece ter evitado a repetição de tragédias como esta, por outro lado favoreceu uma alteração das formas de torcer. Como se afirma no célebre Taylor Report, o relatório que estabeleceu as diretrizes para a reforma dos antigos estádios ingleses, com a instalação dos assentos os espectadores deixam, pois, de entrar fisicamente em contato, permanecendo isolados em seu "[...] pequeno pedaço de território." (TAYLOR, 1989, p. 27). Ou seja, para usarmos os termos de Eric Landowski (2005) e Ana Claudia de Oliveira (2014a), de práticas ajustivas, centradas no fazer juntos, no contágio estésico e no sentir juntos, passa-se a práticas programadas, fundadas na lógica da previsibilidade, do controle e da disciplinarização dos corpos. É o que o geógrafo britânico John Bale (1995) definiu como o modelo do estádio-teatro, onde todos devem permanecer sentados, comportados e possivelmente imóveis até o fim do show.

Paralelemente, os estádios deixam hoje de ser lugares dedicados apenas ao espetáculo do futebol, tornando-se verdadeiros espaços multiuso. Outra mutação, como divulgou em nota a empresa Odebrecht - responsável pela reforma e pela construção de quatro estádios da Copa do Mundo de 2014 - da qual o termo arena tornou-se o marco principal: “[...] o termo arena guarda relação com o conceito de espaço multiuso. Ou seja, pela concepção atual, é possível realizar uma série de eventos não relacionados diretamente ao futebol, como exposições, shows e encontros corporativos" (KACHANI, 2014, doc. não paginado).

Os projetos da Arena Corinthians e da Arena Multiuso Allianz Parque são exemplos emblemáticos desta metamorfose. Como preveem os planos dos dois clubes, os espaços internos dos edifícios serão preenchidos por lojas, bares, restaurantes, museus e memoriais. No que diz respeito ao Allianz Parque, conforme as intenções do Palmeiras e da WTorre, a empresa construtora, o estádio - onde desde 2015 vêm sendo realizados shows e outros eventos esportivos - deverá permanecer aberto durante a semana, atendendo à demanda dos moradores dos bairros de Perdizes e Pompéia, mesmo os que não torcem pelo time de casa. Ou seja, o consumo - de bens e serviços, cultural, gastronômico, etc. - está se afirmando como o motor principal da experiência dos novos estádios paulistanos. É o modelo do estádio-shopping center, onde o futebol torna-se quase um item acessório, deixando de ser o cerne das vivências do lugar, exposto de modo claro e sintético pelo ex-presidente do Corinthians, André Sanchez, que, em uma declaração concedida em 2014 ao The New Yorker, defi-

\footnotetext{
${ }^{1}$ Naquele dia, devido à negligencia da polícia local, que consentiu a lotação do estádio muito além da sua efetiva capacidade, 96 pessoas perderam a vida esmagadas contra as grades que dividiam o campo das arquibancadas.
} 
niu o projeto da Arena Corinthians como um projeto de construção do "maior e melhor shopping center do mundo, com um campo de futebol no meio" (MCGRATH, 2014, tradução nossa).

Dito isso, é possível concluir que os novos estádios tendem a transformar o sertorcedor em um ser-consumidor, ou seja, em um sujeito pelo qual a assunção da identidade clubística não reside mais - ou não apenas - na vivência das arquibancadas, no contágio estésico e na paixão esportiva. Reside, também, no fato de consumir o modelo de pertencimento construído pelo destinador-clube e por outros destinadores a ele relacionados (como a seguradora Allianz, no caso do Palmeiras, que adquiriu os direitos de nomeação da Arena).

Diante desse cenário, percebem-se de modo mais nítido os motivos e as consequências da adoção do termo arena. Sob um perfil estreitamente semiótico-comunicacional, podemos afirmar que tal escolha preenche, deslocando-o em um nível semântico-cognitivo, o déficit de sensibilidade que os novos estádios apresentam em relação aos antigos. Carregando e resgatando o imaginário das arenas romanas - onde, como lembra Sloterdijk (2008), o corpo, a carne e a lógica terrena do sensível prevalecem sobre a razão, a distância e a lógica divina -, o termo projeta na experiência dos novos estádios uma aura de proximidade, convívio e contato, que estes, pela sua própria conformação plástica e figurativa, tendem, na realidade, a negar.

Não por acaso, em linha com o que aconteceu na Europa, a construção das novas arenas, no Brasil, foi acompanhada por uma explosão de textos e discursos que contribuíram, de certa maneira, a suprir esta carência de experiência em carne e osso, ou melhor, a transferi-la no plano da comunicação mediada: sites com visitas virtuais, vídeos promocionais, perfis nos sites de redes sociais (Twitter, Youtube, Facebook, Instagram), onde se consolida um verdadeiro simulacro de presença estésica, do qual o próprio termo arena, com seus ecos míticos-carnais, é a chancela definitiva. No caso do Allianz Parque, em particular, tal sublimação midiática da paixão esportiva é ainda mais evidente. Mais do que no próprio estádio, é na mídia que, conforme os discursos produzidos e divulgados pelo clube e pela construtora, a "torcida", a "família palmeirense", ou melhor, "os consumidores-torcedores" se reconhecem e têm de se reconhecer, estesicamente, enquanto actante coletivo (GREIMAS, $1976)^{2}$.

\footnotetext{
${ }^{2}$ Veja-se, a este propósito, o vídeo \#DeVoltaPraCasa, produzido pela equipe do Allianz Parque, que, no dia da sua inauguração, convidou os torcedores a filmarem seus primeiros momentos na Arena e postá-los nas redes sociais com a hashtag \#DeVoltaPraCasa.
} 
Em suma, traços distintivos dos estádios do Século XX, a estesia e o contato corpo a corpo passam a ser - e devem ser - vividos enquanto reflexos linguísticos, palavras, nomes, transfigurações midiáticos-comunicacionais. Uma estratégia discursiva que, como aponta Trivinho, retomando as propostas de Guillaume (1982) sobre a "comunicação espectral", reflete as dinâmicas de desmaterialização típicas da condição glocal, onde, em certo sentido, “[...] o corpo e toda a materialidade da vida social [...] [são] inoculados e representados na visibilidade mediática por seus equivalentes espectrais." (TRIVINHO, 2011, p. 115).

\section{Naming rights versus apelidos ou da disputa Semiótica pela cidade}

A difusão da denominação de arena em detrimento de estádio dentro e fora do Brasil é apenas um fragmento de um processo mais amplo de mitologização mercadológica dos espaços dedicados à fruição do futebol e de transformação do esporte em fenômeno econômico de escala global, do qual a comercialização dos assim chamados naming rights, os direitos de nomeação dos estádios, constitui o mais nítido e natural desdobramento

Prática consolidada e historicamente radicada nos Estados Unidos, onde arenas de beisebol, basquete e outros esportes carregam nomes de grandes empresas como Sunlife, Barclayes e American Airlines, a venda dos naming rights marcou, na última década, o cenário do futebol europeu e mundial. Alguns casos emblemáticos são aqueles da Allianz Arena de Munique, construída em 2006 em ocasião da Copa do Mundo da Alemanha; do Emirates Stadium, do Arsenal, erguido em Londres em 2006; do Etiahd Stadium, do Manchester City, na cidade homônima; e do Reebok Stadium, do Bolton Wanderers.

Normalmente, além dos direitos sobre o nome, os contratos preveem uma serie de benefícios adicionais, entre os quais a possibilidade de estampar o nome da empresa nos ingressos e nas camisas dos funcionários, de instalar estandes e lojas no interior do estádio, de ter estacionamentos e camarotes privativos para seus clientes (ASHLEY; OHARA, 2001).

No Brasil, o primeiro clube a assinar um contrato de naming rights foi o Atlético $\mathrm{Pa}$ ranaense, que em 2005 cedeu os direitos de nomeação do estádio Joaquim Américo Guimarães, conhecido popularmente como Arena da Baixada, para a Kyocera, empresa japonesa que atua no ramo da eletrônica. Em tempos mais recentes, em 2013, a marca Itaipava adquiriu do Governo do Estado da Bahia os direitos para a Arena Fonte Nova, em Salvador, que passou a se chamar Itaipava Arena Fonte Nova, assim como a seguradora alemã Allianz comprou aqueles da nova arena do Palmeiras, em São Paulo, chamada hoje Allianz Parque. 
No entanto, é preciso lembrar que, apesar de ser uma novidade para os estádios, a comercialização de nomes de edifícios destinados ao lazer não representa uma opção de marketing desconhecida no contexto brasileiro, sobretudo em São Paulo. Há anos bancos vêm associando seus nomes a cinemas (Unibanco, Itaú), teatros (Bradesco) e casas de show (Credicard Hall, Citibank Hall). A entrada do Allianz Parque nesse cenário configura-se, portanto, como um passo ulterior rumo à privatização da cidade e, em particular, dos topônimos da cidade. Uma questão que convida a refletir de forma mais ampla sobre as estratégias de manipulação e de apropriação da vida sociocultural em São Paulo por parte do poder privado. Mais especificamente sobre a assunção, por parte do mercado, do papel de destinador não apenas dos clubes e de seus torcedores, mas também da cidade entendida, ao mesmo tempo, enquanto sujeito e espaço semiótico em disputa (LOTMAN, 1985; MACHADO, 2015); sobre as consequências da entrada em cena das novas nomeações nos espaços físicos e na memória da cidade, que trazem à tona as relações de poder e, em particular, as dinâmicas de centralização e periferização, de visibilização e invisibilização - isto é, esquecimento (LOTMAN; USPENSKIJ, 1975; LOTMAN, 1985, 1993) - do universo cultural paulistano e brasileiro; e sobre os mecanismos de resistência a estas tendências homogeneizantes (LOTMAN, 1985; 1990) das quais, como dissemos na Introdução, o caso da Arena Corinthians é emblemático.

\subsection{Allianz Parques: destinadores e morfologias da cidade- compartimentada}

Em seu ensaio Mito - nome - Cultura, Lotman e Uspenskij (1975) evidenciam como projeto de uma Rússia nova implantado pelo czar Pedro I em seu reinado, de 1682 a 1721 e que, segundo os autores, se alastrou por todo o século XVI e o começo do século XVII - foi caracterizado por um processo geral de renomeação do aparato simbólico estatal e, em particular, dos antigos topônimos nacionais, que se tornaram permeáveis às influências de culturas e idiomas estrangeiros. Significativo, a este propósito, o caso de Petersburgo (Peterburg), nome de origem germânica, que foi eslavizado no começo do Século XX (Petrograd) para chegar enfim à forma atual após a morte de Lenin: São Petersburgo.

Esses são fenômenos comuns na história das culturas. Entre os exemplos, estudados em âmbito semiótico, está a italianização dos nomes próprios sardos (SEDDA, 2012) e a norte-americanização dos topônimos de Pristina, capital do recém-fundado estado do Kosovo, 
cuja avenida principal recebeu, após a proclamação da independência, em 2008, a denominação de Boulevard Bill Clinton (DEMURU; ALBERTINI, 2011).

Os casos que acabamos de citar não se distanciam muito daquele que estamos aqui analisando. A entrada, no cenário do futebol brasileiro - e na cena metropolitana de São Paulo - do negócio dos naming rights, alimentou, pois, e continua hoje alimentando, uma transformação radical do universo dos topônimos urbanos, que tem algumas importantes consequências em outras esferas da sociedade e da cultura paulistana e brasileira. Vejamos em detalhe.

No Século XX, a nomeação oficial e a apelidação dos estádios respondia a dois princípios semióticos específicos:

a) de um lado, a um princípio monumental-institucional, que visava, por meio da homenagem a personagens importantes em sua história, à celebração dos clubes e do futebol. É o caso do Estádio Cícero Pompeu de Toledo, do São Paulo Futebol Clube, que comemora a figura do homônimo presidente que, em suas últimas gestões, promoveu a realização da obra; do Estádio Municipal do Pacaembu, construído em 1940 por vontade do então presidente Getúlio Vargas, que em 1961 passou a ser chamado Estádio Paulo Machado de Carvalho, em homenagem ao chefe da delegação brasileira nas vitoriosas Copas do Mundo de 1958 e 1962, também conhecido como Marechal da Vitória; do Estádio Palestra Itália, da atual Sociedade Esportiva Palmeiras (antigo Palestra Itália), inaugurado em 1933, que atestava a origem e a história do clube e cujo nome permaneceu intacto mesmo quando Vargas, durante a segunda guerra mundial, obrigou os times brasileiros que faziam menção às chamadas potências do Eixo (Itália, Alemanha e Japão), contra as quais Brasil tinha se engajado, reforçando, com suas tropas, o contingente dos Aliados, a trocarem de nome;

b) do outro, a um princípio geográfico-informal, que fazia referência ao locus em que os estádios encontravam-se - e encontram-se - situados, como demonstram os casos do Estádio Municipal do Pacaembu, primeiro nome oficial, como acabamos de mostrar, do Estádio Municipal Paulo Machado de Carvalho, que ainda hoje é chamado dessa forma na imprensa e no imaginário coletivo paulistano; do Estádio Cícero Pompeu de Toledo, melhor conhecido como Morumbi, o nome do bairro em que foi erguido; do Estádio Palestra Itália, o atual Allianz Parque, que desde a sua fundação, tanto nas placas colocadas no entorno do estádio (que ainda hoje permanecem), quanto no dia a dia da vida da cidade, respondia muitas vezes ao nome de Parque 
Antártica, devido ao homônimo parque de lazer ali construído, em 1902, pela Companhia Antártica, que se tornou, nos primeiros anos do Século XX, um dos principais campos de futebol de São Paulo.

Em termos greimasianos, é possível afirmar que tais definições revelam a atestação de um desejo de autodestinação, seja dos clubes, seja de São Paulo, seja, em certa escala, do Brasil. Celebrando personagens que construíram as histórias das agremiações esportivas (Cícero Pompeu de Toledo) e do esporte nacional (Paulo Machado de Carvalho), ou, ainda, divulgando e legitimando, no cenário midiático nacional e internacional, suas coordenadas geográficas, os nomes oficiais e os apelidos dos estádios operam e afirmam-se, neste cenário, enquanto marcas de uma autodescrição (LOTMAN; USPENSKIJ, 1975; LOTMAN, 1985; 1993) bem-sucedida, de uma narrativa de autorreconhecimento e autoidentificação, em que determinados sujeitos (clubes, cidade e país) constroem suas próprias tramas de valores, manifestando, ao mesmo tempo, sua individualidade e seu pertencimento a uma comunidade (os clubes à cidade, a cidade ao país). Como lembra Lotman (1993), a escolha de um nome próprio determina, pois, não apenas os limites da consciência individual, mas também, em um jogo de recíproca articulação entre as duas, aqueles da consciência coletiva.

Com a prática dos naming rights - isto é, com o surgimento do Allianz Parque e com a possível compra por outra empresa dos direitos de nomeação da Arena Corinthians - este cenário muda radicalmente. Passa-se de um sistema de nomes-próprios materiais-locais, referentes a pessoas-físicas e lugares, a um sistema de nomes próprios imateriais-globais, referentes a pessoas-jurídicas e entidades comerciais multinacionais. Uma passagem que revela:

a) uma troca de destinação próxima àquelas descritas por Lotman e Uspenkij em relação à Russia ou por Sedda em relação à Sardenha, em que sujeitos inicialmente autodestinados (os clubes e a cidade) passam a ser movidos por destinadores externos (o poder privado e o mercado), assumindo, em parte ou em sua totalidade, os valores e os programas narrativos que eles defendem e propõem;

b) por consequência, o seu englobamento nos confins de uma outra semiosfera - no nosso caso, a semiosfera ou, nos termos de Appadurai (1996, p. 33), o "panorama" mercadológico global, da qual os primeiros controlam as narrativas e as estruturas de poder.

Como acenamos anteriormente, se, no que diz respeito ao âmbito do futebol paulistano, tal transnomeação é algo relativamente recente, no que tange às lógicas de definição 
dos topônimos de outros espaços de cultura e lazer de São Paulo suas raízes são muito mais profundas e antigas. Nesse sentido, somando-se aos vários Citibank Hall, Credicard Hall, Itaú Cinemas e Teatros Bradescos, o Allianz Parque reforça a perda de domínio da cidade sobre si mesma e a sua dependência do poder privado, que se impõe, cada vez mais, como seu verdadeiro destinador. Ou seja, nas palavras de Sedda, estamos diante de uma

[...] impossibilidade, para um sujeito, de assumir ou preservar um nome próprio [que] remete à impossibilidade, para uma cultura, de reproduzir seus signos, suas práticas e seus valores e é, portanto, indicativa de um processo político de englobamento e absorção de uma dada semiosfera por parte de uma outra. (SEDDA, 2012, p. 424, tradução nossa)

A este propósito, é interessante observar, ainda, como a venda dos naming rights responde às mesmas lógicas de comercialização dos espaços físicos dos estádios descritos na seção anterior, ao modelo do estádio shopping center defendido por André Sanchez, do qual os novos nomes constituem uma peça ulterior - ou, talvez, a atestação derradeira.

No entanto, estes não parecem ser seus únicos efeitos na vida e na geografia de São Paulo. Além de confirmar o papel de destinador forte do poder privado, os naming rights parecem corroborar, ao mesmo tempo, o modelo de desenvolvimento urbano vigente hoje na cidade, que poderíamos definir cidade-compartimentada, onde a vida se passa dentro de blocos autônomos e isolados, de caixas fechadas autossuficientes (o condomínio, o shopping center, o clube, o estádio e assim por diante) que não se abrem e não dialogam com o externo (CALDEIRA, 2000). Uma cidade altamente programada (LANDOWSKI, 2005), que separa e valoriza as suas partes em detrimento do todo e das conexões entre elas.

O que, então, os novos nomes próprios dos estádios e dos espaços culturais paulistanos têm a ver com este modelo de cidade?

Como afirmam Lotman e Uspenkij, o significado geral dos nomes-próprios, "reduz-se a um mito" (LOTMAN; USPENKIJ, 1975, p. 89-90, tradução nossa). Consequentemente, um universo articulado e coerente de nomes-próprios forma, por sua vez, um "espaço mitológico" (LOTMAN; USPENKIJ, 1975, p. 89-90, tradução nossa).

Ora, continuam os autores, ocorre que a tal universo mitológico corresponde:

[...] uma concepção especificamente mitológica do espaço, que não se apresenta sob a forma de um continuum marcado por traços distintivos, mas como um conjunto de objetos marcados por nomes-próprios. A consequência disso é que nos intervalos entre estes o espaço parece se interromper. (LOTMAN; USPENKIJ, 1975, p. 89-90, tradução nossa)

É exatamente esta a tipologia de espacialidade urbana que a difusão dos Allianz Par- 
ques e dos Citibank Halls, junto à ação da televisão e da mídia impressa e digital, que os destacam e o enaltecem enquanto sinédoques da cidade, proporcionam: uma espacialidade em que se celebra a mitologia da semiosfera mercadológica-midiática global, que reduz a cidade a uma serie desconexa de pontos emblemáticos, de blocos autárquicos, de "monumentoslogo" (PEZZINI, 2006, p. 44) ou, para usarmos a expressão que o próprio Palmeiras utilizou para definir seu novo estádio, de cartões-postais nomeados pelo mercado e iluminados pela mídia, em volta dos quais proliferam, áreas de esquecimento e invisibilidade. Exemplar, a este propósito, o caso da capa da Revista Veja de 5 novembro de 2014, onde o estádio, clareado pelos seus próprios holofotes, brilha como um verdadeiro spotlight, único ponto de luz em meio ao fundo escuro de uma cidade que ele mesmo torna inteiramente invisível.

\subsection{Parques, ruas e estádios: topônimos, memórias e relações de poder na cidade}

Começamos a entrever, na seção anterior, como os processos de atribuição de nomes próprios aos espaços e aos edifícios da cidade revela uma disputa Semiótica latente em todo o território paulistano: aquela pela apropriação da urbe por parte de subjetividades diversas que operam em diferentes semiosferas. Uma disputa em que, por enquanto, o poder privado parece ocupar uma posição privilegiada.

No entanto, este conflito manifesta, ao mesmo tempo, tensões de outro tipo, que não dizem respeito apenas ao presente da metrópole, mas também ao seu passado, à luta pela sua memória e, como procuraremos mostrar, pela memória da diversidade do povo paulistano e, em certa escala, do povo brasileiro.

Mais uma vez, o caso da venda dos naming rights do Allianz Parque é, a este respeito, altamente significativo.

O nome da arena foi estabelecido em 2013 por meio de uma votação on-line, que previa que os palmeirenses interessados pudessem escolher entre três opções disponibilizadas pelo clube em parceria com a seguradora: Allianz 360, Allianz Center e Allianz Parque. A primeira recebeu $4,1 \%$ dos votos, a segunda $7,17 \%$ e a terceira $88,73 \%$, ganhando, assim, o concurso (ALLIANZ, 2013). No entanto, a escolha definitiva causou o descontento de boa parte da torcida, que se manifestou publicamente por meio das redes sociais. Divulgando e promovendo a hashtag \#AllianzPalestraJá, que se tornou trending topic no Twitter, os palmeirenses insatisfeitos defendiam a necessidade de manter, no novo nome do estádio, parte 
da sua antiga denominação, em particular, o vocábulo italiano Palestra, marco, até então, da história do clube e de suas conquistas. Contudo, os protestos não tiveram êxito.

A história confirma o que dissemos a respeito da perda de controle, por parte do clube, sobre suas narrativas identitárias e suas memórias, que passam, agora, sob a égide de um destinador externo. Um destinador que, para se afirmar enquanto tal, é obrigado, em primeiro lugar, a apagar os marcos e os traços distintivos de seus possíveis concorrentes. Diante da possibilidade de não conseguir impor seu nome e seu logotipo no imaginário coletivo palmeirense, paulistano e brasileiro - algo que aconteceu, como veremos em breve, com a Arena Corinthians - a Allianz optou, então, por se preservar. Como bem resumiu Marcos, ex-goleiro do Palmeiras no momento da votação, em que declarou a sua preferência pela opção Allianz Parque: "Gostei [de Allianz Parque, ndr.]. Acho que o pessoal tirou o Palestra senão iam continuar a chamar de Palestra Itália. Não quero incentivar ninguém, mas acredito que esse Parque deva ganhar. Até pela alusão ao Parque Antártica antigo" (FARINA, 2013).

A estratégia discursiva da seguradora é, portanto, eficaz e sutil. Por meio de uma escolha que remete a uma memória remota do clube, a Allianz consegue, ao mesmo tempo, certificar o seu compromisso com a história do Palmeiras e impor com força sua identidade. O termo parque garante a estabilidade desta dúplice manobra. Como explicou Marcos, além de lembrar o antigo Parque Antártica, o vocábulo é, em relação ao italiano palestra, um nome semanticamente mais neutro e potencialmente polissêmico, que, com o passar dos anos, será cada vez mais associado à empresa (e não ao Palmeiras).

Todavia, o que, em relação aos objetivos traçados na Introdução do artigo, é interessante evidenciar, é o fato de que essa disputa entre a torcida palmeirense e o novo patrocinador do clube recaiu sobre a memória da cidade e do Brasil.

Em 22 de abril de 2015, a Câmara Municipal de São Paulo sancionou um projeto de lei que propunha a mudança de nome do trecho da Rua Turiassu, situado entre as ruas Cayowáa e Carlos Vicari (G1), que, no dia 12 de junho do mesmo ano, após uma cerimônia de inauguração que contou com presença de Paulo Nobre, presidente do Palmeiras, passou oficialmente a se chamar Rua Palestra Itália. Uma operação que vai ao encontro da escolha de manter intacto, em sua locação originária, na parte central da mesma rua, o antigo portão do estádio, onde ainda se encontra escrito Estádio Palestra Itália.

Do ponto de vista propriamente semiótico, trata-se de uma transformação decisiva. Estamos diante de um processo de reorganização dos arranjos discursivos que explicitam as 
hierarquias e as relações de poder da cidade, de uma verdadeira luta semiopolítica em que os sujeitos envolvidos procuram manter um lugar e garantir, na maior medida possível, sua visibilidade. Enquanto a Allianz se apropria do nome do estádio do Palmeiras, o Palmeiras se apropria do nome da Rua em que o Allianz Parque está situado, conferindo-lhe o nome de seu antigo estádio e salvando sua memória, a qual, contudo, passa a ser relegada em um lugar de segundo plano.

Vale ressaltar como esta hierarquia se expressa também sob o ponto de vista plástico: na configuração topológica do entorno do estádio, tanto as placas da rua quanto o portão do clube que carregam o nome Palestra Itália ocupam, pois, uma posição inferior e um espaço menor em relação às placas e aos logos do Allianz Parque, visível a partir de diversas posições e de diversos metros de distâncias.

No entanto, os efeitos de inserção dos logos do Allianz Parque na ex-Turiassu envolvem questões que vão além daquelas relativas aos espaços e à memória da rua e da cidade, abrangendo, como dizíamos, os processos de configuração discursiva da nação brasileira.

De fato, as verdadeiras vítimas deste novo encaixe de nomeações não são o Palestra Itália e o Palmeiras, mais sim aquelas culturas que há tempo vêm sendo excluídas das narrativas de autodescrição do Brasil: as culturas indígenas, pelas quais a toponomástica representa, muitas vezes, um dos poucos lugares de sobrevivência Semiótica.

Portanto, da mesma forma como promoveram o apagamento da cidade, tornando-a, como demonstra a capa da Revista Veja previamente citada, invisível, os novos estádios promoveram também um apagamento cultural. Como dizia Lotman (1975, p. 31, tradução nossa), se a historia da humanidade pode ser considerada uma luta pela memória, não é casual que "[...] a destruição de uma cultura se manifeste como destruição da memória, aniquilação de textos e esquecimento dos nexos".

\section{Itaquerão: apelidos e resistências}

Em diversos momentos da sua produção intelectual, Lotman $(1985,1993)$ explicou que a semiosfera é caracterizada por duas tendências opostas e, ao mesmo tempo, complementares:

a) de um lado, por tendências homogeneizantes, que visam estabelecer nexos e articulações entre os diferentes pedaços da cultura e, ao mesmo tempo, a conferir uma forma aos nexos e às articulações que produzem - orientadas, ou seja, para a cons- 
trução de autodescrições ou meta-modelos culturais coesos e internamente coerentes;

b) do outro, por tendências heterogeneizantes, que aspiram à contínua reformulação dos modelos e das conexões constituídas, gerando caos no interior da semiosfera e garantindo, assim, sua evolução.

Trata-se de tendências análogas àquelas implícitas no conceito de glocalização, assim como postulado por um de seus criadores, o sociólogo Roland Robertson, segundo o qual o termo "registra a co-presença de identidades e diferenças, como também a intensa e recíproca penetração entre o local e o global, o universal e o particular, a homogeneidade e a heterogeneidade" (ROBERTSON; GIULINOTTI, 2009, p. 60, tradução nossa), ou ainda, em noções como aquela de "fragmegration", do cientista político James Rosenau, que "captura, em uma única palavra, a interação invasiva entre dinâmicas de integração e de fragmentação, que se desenvolvem em todos os níveis de uma comunidade" (ROSENAU, 2003, p. 11, tradução nossa).

O que, no entanto, tais dinâmicas têm a ver com a venda dos naming rights dos estádios e os processos de renomeação de São Paulo que estamos aqui procurando descrever?

Ora, se é verdade, por um lado, que existem em São Paulo tendências que visam construir um sistema homogêneo e coerentemente interferindo de nomes próprios referentes à semiosfera do poder privado - que constitui, de certo modo, a camada mais evidente e articulada de sua autodescrição -, é preciso ressaltar, por outro lado, que há também tendências opostas, que parecem ameaçar a primazia das primeiras.

É o que nos dizem as diversas tentativas de venda dos naming rights da Arena Corinthinas, que, até agora, no momento em que escrevemos, não tiveram êxito positivo.

Segundo a diretoria do clube, este insucesso deve-se ao operado da imprensa paulistana e brasileira, que, a partir do momento em que foi oficializada a sua construção, começou a chamar o estádio por um apelido aumentativo: Itaquerão, que alude à sua localização geográfica, no bairro de Itaquera, na Zona Leste da cidade (PEREIRA, 2014) .

De fato, por meio de uma rápida busca em todos os arquivos dos principais jornais do país, é possível perceber que o nome tem uma série infinita de ocorrências. No entanto, vale ressaltar que, em um primeiro momento, que coincide, grosso modo, com a abertura, em 2011, do canteiro da Arena, o apelido tornou-se conhecido graças a iniciativa de alguns torcedores corinthianos, que criaram o site www.itaqueraoaovivo.com.br, que reproduzia, 24 horas ao dia, os avanços da obra. 
Não nos interessa reconstruir em detalhe as trajetórias e os ecos - multíplices - do debate em torno do nome da Arena Corinthians nas mídias e nas redes sociais. Para ter uma ideia do tamanho que atingiu, é suficiente lembrar um post publicado no site da rede social Facebook em 22 de outubro de 2011, por José Simão, em que o jornalista humorístico afirmava: "O Itaquerão é o estádio com mais apelidos do Brasil: Gambazão, Diferenciadão, Malocão, Faixa de Gaza e Arena Mãos ao Alto." (SIMÃo, 2011).

0 que queremos frisar é o fato de que, como acabamos de acenar, a imposição do apelido no panorama midiático nacional contribuiu, ao menos até hoje, a amortecer a hegemonia da semiosfera mercadológica multinacional sobre a cidade e a cultura paulistana e brasileira.

Nesse sentido, parece possível afirmar que Itaquerão, independentemente das intenções reais ou fictícias que estão por trás da sua difusão, reflete, para usarmos os termos de Michel de Certeau (1994, p. 45), uma "tática" de resistência da esfera local paulistanabrasileira contra as "estratégias" de domínio da esfera global, o marco de uma dinâmica de heterogenização que se opõe, em certa medida, às tendências homogeneizantes em ato em São Paulo e no Brasil. Em uma cidade e um em país onde os apelidos constituem parte fundante do processo de identificação linguística e cultural, "lucrar com Itaquerão", pode se revelar, como foi dito, um grande desafio (LEPIANI, 2012).

E não apenas isso. A afirmação do apelido aponta, ao mesmo tempo, para as formas de existência e resistência de uma precisa tipologia de memória que Lotman define, não por acaso, "memória criativa" (LOTMAN, 1996, p. 158) - isto é, uma memória capaz de atualizar e ressemantizar, de maneira sinuosa e inusitada, configurações de sentido sedimentadas. Como no caso da memória da arte - que para o semioticista representa o caso exemplar de memória criativa - estamos aqui diante de um processo heterogeneizante de recordação cultural que se opõe, quebrando-as, às tendências homogeneizantes da semiosfera, as quais configuram, por sua vez, uma tipologia de memória meramente "informativa", que visa "a conservação dos resultados finais de uma certa atividade cognoscitiva" (LOTMAN, 1996, p. 158, tradução nossa) - como no caso dos Allianz Parque e de seus efeitos na memória paulistana e brasileira.

Em termos mais teóricos, como lembra Sedda (2012), a copresença de tais dinâmicas no interior da semiosfera dá origem, portanto, a um movimento que lembra o movimento de um acordeão, isto é, um movimento em que se alternam momentos de construção de isomorfismos e nexos coerentes (isotopias, poderíamos dizer em termos greimasianos) entre 
as diferentes partes do sistema cultural (no nosso caso, a isotopia dos nomes-próprios mercadológicos: Allianz Parque, Citibank Halls, Teatros Bradesco, Bikes Itaú) a momentos em que essas conexões são colocadas em crise (como no caso do Itaquerão). Um ritmo que, visto de perto, assume os contornos "de uma pulsação contínua, de um continuo ferver, que faz da semiosfera um mecanismo vivo, autopoiético e em perene transformação" (SEDDA, 2006, p. 45, tradução nossa), parecido, como vimos, com os processos de glocalização descritos em outros âmbitos das ciências sociais, do qual a disputa entre naming rights e apelidos constitui, sem dúvida, um marco exemplar.

\section{Conclusões}

Em boa parte, a história contada nas páginas anteriores pode ser definida "uma história de dominância" (SEDDA, 2012, p. 162). Ou melhor, uma tentativa de construir uma narrativa dominante.

Reformulando em chave histórico-antropológica o conceito de dominante elaborado em âmbito linguístico por Roman Jakobson, Lotman (1985) tem refletido sobre as manifestações semióticas do poder. Se, para Jakobson (1987, p. 41, tradução nossa), a dominante é o elemento chave do texto "que determina e transforma os outros componentes", garantindo assim a coesão da estrutura textual e interpretativa, para Lotman representa, ao contrário, um mecanismo inteligente de gestão narrativa da heterogeneidade e do caos internos à semiosfera, por meio do qual uma determinada subestrutura submete as outras à sua organização - isto é, aos seus códigos e ao seu sistema de valores. Como afirma o autor:

A assunção de um papel dominante por parte de uma subestrutura, que submete todas as outras à suas organização, adquire o direito de falar em nome do objeto cultural dado, produzindo, enfim, uma autodescrição metalinguística da linguagem da cultura, que elimina tudo que se contrapõe a tais sub-estruturas, definindo-o enquanto extra-sistémico (LOTMAN, 1985, p. 132, tradução nossa).

A dominante surge, portanto, como uma instância de codificação do universo cultural: uma porção local se ergue à metalinguagem da descrição da cultura enquanto tal, funcionando como um verdadeiro "centro cultural territorial que se comporta como a subestrutura dominante da descrição de Jakobson" (LOTMAN, 1985, p. 133). Para quem não se submete às normas estabelecidas, o risco é cair silenciosamente na invisibilidade e no esquecimento.

Trata-se, no entanto, de uma tendência que sempre encontra esferas e momentos de 
resistência, pois, é o caso de lembrar, para Lotman, se, por um lado, a semiosfera tende constantemente à definição de uma unidade ideal, pelo outro ela necessita de áreas de diversidade e complexidade, que constituem a condição sine qua non de sua existência e evoluções futuras.

É o que parece sugerir o conflito entre a cada vez mais consistente afirmação dos naming rights na cena paulistana - que atesta a dinâmica de apropriação da cidade por parte do poder privado global - e os diversos insucessos relativos à venda dos direitos de nomeação da Arena Corinthians, do qual, segundo a própria diretoria do clube, a difusão de seus apelidos seria a causa principal. A este propósito, talvez não seja casual o fato de que, já em 2012, o Corinthians tenha registrado Itaquerão no Instituto Nacional da Propriedade Industrial (INPI) e, mais recentemente, em 2016, Arena do Povo. Seria, enfim, uma nova etapa desta disputa?

\section{Referências}

ALLIANZ. Nova arena já tem nome: Allianz Parque. Disponível em:

<https://www.allianz.com.br/web/azb-site-allianz/-/azb-site-na-nova-arena-ja-tem-nomeallianz-parq-2>. Acesso em: 12 set. 2016

APPADURAI, Arjun. Modernity at large. Cultural dimensions of globalization. MinneapolisLondon: University of Minnesota, 1996.

ASHLEY, Greg; OHARA, Micheal. Valuing Naming Rights. In: ANNUAL MEETING OF THE ACADEMY OF LEGAL STUDIES IN BUSINESS, 76., 2001, Albuquerque. Proceedings... Albuquerque, 2001. p. 1-24.

BALE, John. The stadium as theatre, a metephor of our time. In: BALE, John; OMEN, Olef (Org.). The stadium and the city. Keele: Keele University, 1995. p. 311-322.

CALDEIRA, Teresa. Cidade de muros: crime, segregação e cidadania em São Paulo. São Paulo: Editora 34, 2000.

CERTEAU, Michel de. A invenção do cotidiano: artes de fazer. Petrópolis: Vozes, 1994.

DEMURU, Paolo. Essere in gioco. Calcio e Cultura tra Brasile e Italia. Bologna: Bup, 2014

DEMURU, Paolo; ALBERTINI, Matteo. The independence of Kosovo. A semiotic stance on glocalization. In: AXFORD; Barrie; HUGGINS, Richard. Culture and/of glocalization. Cambridge: Cambridge Scholar Publishing, 2011.

FARINA, Allan. Marcos escolhe Allianz Parque e diz que quer jogar na nova arena. Terra, 29 abr. 2016. Disponível em: <https://esportes.terra.com.br/palmeiras/marcos-escolhe- 
allianz-parque-e-diz-que-quer-jogar-na-nova-

arena,78056dd95b65e310VgnVCM4000009bcceb0aRCRD.htmlZ>. Acesso em: 14 set. 2016

FLOCH, Jean Marie. Identités visuelles. Paris: PUF, 1995

G1. Câmara de São Paulo aprova alterar nome da Rua Turiassu para Palestra Itália. 10 mar. 2015. Disponível em: <http://g1.globo.com/sao-paulo/noticia/2015/03/camara-aprovaalterar-nome-da-rua-turiassu-em-sp-para-palestra-italia.html>. Acesso em: 15 set. 2015

GEERTZ, Clifford. The interpretation of cultures. Selected essays. New York: Basic Books, 1973.

GREIMAS, Algirdas Julien. Semiótica e ciências sociais. São Paulo: Cultrix, 1976.

GREIMAS, Algirdas Julien ; COURTÈS, Jacques. Sémiotique. Dictionnaire raisonné de la théorie du langage. Paris: Hachette, 1979.

GREIMAS, Algirdas Julien. Semiótica figurativa e semiótica plástica. In: Significação Revista Brasileira de Semiótica, Araraquara, n. 4, p. 18-46, jun. 1984.

JAKOBSON, Roman. Language in literature. Cambirdge, Massachusetts: Belknapp, 1987.

KACHANI, Morris. Arenas x estádios. Folha de São Paulo, 31 jul. 2014. Disponível em: < http://www1.folha.uol.com.br/fsp/esporte/178479-arenas-x-estadios.shtml>. Acesso em : 10 set. 2016

LANDOWSKI, Eric. Les interactions risquées. Limoges: Pulim, 2005.

LEPIANI, Giancarlo. No país dos apelidos, o desafio de lucrar com um "Itaquerão". Revista Veja. Disponível em: http://veja.abril.com.br/esporte/no-pais-dos-apelidos-o-desafio-delucrar-com-um-itaquerao>. Acesso em: 15 set. 2016.

LOTMAN, Jurij Michajlovič. La semiosfera. L'asimmetria e il dialogo nelle struture pensanti. Venezia: Marsilio, 1985.

LOTMAN, Jurij Michajlovič. Universe of the mind. A semiotic theory of culture. Bloomington: Indiana University Press, 1990.

LOTMAN, Jurij Michajlovič. La cultura e l'esplosione. Prevedibilità e imprevedibilità. Milano: Feltrinelli, 1993.

LOTMAN, I. M. La semiosfera I: semiótica de la cultura y del texto. Valência: Frónesis Cátedra, 1996.

LOTMAN, Jurij Michajlovič; USPENKIJ, Boris. Tipologia della cultura. Milano: Bompiani, 1975.

MACHADO, Irene. Variáveis semióticas do espaço na cultura de meios. Galáxia, São Paulo, v. 29, p. 70-82, 2015. 
McGRATH, Ben. Samba Soccer. Transformation of Brazil's most storied team. The New Yorker, New York, January 2014. Disponível em:

<http://www.newyorker.com/magazine/2014/01/13/samba-soccer>. Acesso em: 25 ago.2016.

OLIVEIRA, Ana Claudia de (Org.). Semiótica Plástica. São Paulo: Hackers, 2004

OLIVEIRA, Ana Claudia de. Interação e sentido nas práticas de vida. Revista Comunicação, mídia e consumo. São Paulo, v. 11, n. 31, p.179-198, 2014a.

OLIVEIRA, Ana Claudia de (Org.). São Paulo público-privado. Uma abordagem sociossemiótica. São Paulo: Estação das Letras e Cores, 2014b.

PEREIRA, Mauro Cesar. Palmeiras vende naming rights. Corinthians não consegue e acusa imprensa porque povo consagra Itaquerão. ESPN, 18 mai. 2014. Disponível em: <http://espn.uol.com.br/post/411418_palmeiras-vende-naming-rights-corinthians-naoconsegue-e-acusa-imprensa-porque-povo-consagra-itaquerao>. Acesso em: 13 set. 2016.

PEZZINI, Isabella. Visioni di Città e Monumenti Logo. In: PEZZINI, Isabella; MARRONE, Gianfranco. Senso e metropoli. Roma: Meltemi, 2006.

ROBERTSON, Roland; GIULIANOTTI, Richard. Globalization and football. London: Sage, 2009.

ROSENAU, James. Distant proximities. Dynamics beyond globalization. Princeton: Princeton University Press, 2003

SEDDA, Franciscu. Introduzione. In: LOTMAN, Jurij. M. et al. Tesi per una semiotica delle culture. Roma: Meltemi, 2006.

SEDDA, Franciscu. Imperfette traduzioni. Roma: Nuova Cultura, 2012.

SIMÃO, José. Facebook. Disponível em:

<https://www.facebook.com/macacosimao/posts/238044176253483>. Acesso em: 14 set. 2016.

SLOTERDIJK, Peter. Spielen mit dem, was mit uns spielt. Neue burcher beitung, 2008. Disponível em: < http://www.nzz.ch/spielen-mit-dem-was-mit-uns-spielt-1.758795>. Acesso em: 31 ago. 2016.

TAYLOR. Peter. The Hillsborough stadium disaster. Final Report. London: HMSO, 1989.

TRIVINHO, Eugenio. Visibilidade mediática, melancolia do único e violência invisível na cibercultura: significação social-histórica de um substrato cultural regressivo da sociabilidade em tempo real na civilização mediática avançada. Matrizes, São Paulo, v. 2, p. 111-125, 2011. 
VICTORINO, Vinícius. Principal empecilho dos naming rights no Brasil é a imprensa, diz André Sanchez. Época Negócios. Disponível em: < http://epocanegocios.globo.com/Essa-ENossa/noticia/2013/11/principal-empecilho-dos-naming-rights-no-brasil-e-imprensa-dizandres-sanchez.html>. Acesso em: 10 set. 2016

\title{
Arenas, naming rights and nicknames: discursive strategies and city-patterns around the communication of Allianz Parque and Arena Corinthians
}

\begin{abstract}
Based on a dialogue between Greimas and post-Greimas's discursive Semiotics and Lotman's Semiotics of culture, as well as in approaches which defend the complementarity between the two of them and the more specific confrontations with studies on glocalization, this article intends to reflect on the names and naming processes of two of São Paulo's new stadiums: Arena Corinthians and Allianz Parque. Three are the matters which interest us in this discussion: the implicit semiotic-communication consequences in the passage from the definition of stadium to the denomination of arena; the reiteration, in the city, of the international market tendency which foresees the sale of the naming rights of stadiums to private companies; and the implicit resistance against such tendency manifested through media's celebration of the nickname Itaquerão - reason for which, according to its board of directors, the club had not yet been able to sell the Arena's naming rights.
\end{abstract}

\section{Keywords}

Stadiums. Arenas. Naming rights. Greimas. Lotman.

Recebido em 11/09/2016

Aceito em 20/10/2016 